\title{
TESTING HABITABILITY FOR SUSTAINABLE BUILDING DESIGN
}

\author{
Rolando-Arturo Cubillos-González
}

\author{
Catholic University of Colombia
}

e-mail: racubillos@ucatolica.edu.co

\begin{abstract}
This paper studied the concept of the habitability of buildings as a sustainability factor in the living environment, particularly in the city of Bogotá. The habitability factor stems from the relationship between human beings, the cultural dimension and the environment. Thus, we can say that the habitability factor is an important element in the building design process. Currently in Bogotá there are buildings that do not meet the requirements of the population. In Bogotá only $40 \%$ of buildings are of a good quality and a great number of newly produced buildings have made for lower quality living spaces. Consequently, it is important to give an adequate response to these kinds of demands. For thase reasons, this study created a model to evaluate the habitability factor of buildings. This model gives some guidelines for designing sustainable buildings and implementing stategies to design a better urban habitat. Finally, the Habitability model was tested as a pilot in the Primero de Mayo neighbourhood, which is located in the fourth district of Bogotá. The neighbourhood was classified as a cultural heritage site by city hall.
\end{abstract}

Key words: building design, Sustainable buildings, Sustainable Models, habitability, Sustainability.

\section{INTRODUCTION}

This paper studied the concept of the habitability of buildings as a sustainability factor in the living environment. For example, in Bogotá (Colombia) $70 \%$ of buildings are residential (Escallón-Gartner \& Villate-Matiz, 2013, p. 251). Only 40\% of these buildings are of a good quality. Also, the growing population of Bogotá creates a greater demand for resources and energy. Furthermore, a great number of constructed buildings in Bogotá have been made for lower quality living spaces. Therefore the habitability factor is an important element in the building design process (Edwards, 2005).

Consequently, Consequently, living conditions in the city of Bogotá need to change (Arévalo, 2014). Therefore, design strategies which make buildings sustainable in the long term should be generated (Ozuna \& Rivera, 2012). Finally, this paper proposes a Model of Habitability that evaluates the habitability factor of buildings. This model was applied in the Primero de Mayo neighborhood as a pilot to test the Habitability factor.

This neighborhood is located in the fourth district of Bogota and it was clasified as a cultural heritage site of the city. However, it is currently undergoing a series of transformations that may affect its habitability in the future. The objective of this paper is to give some guidelines for the building designs process. This paper will now explain the concept of habitability and and show the application of the model in the Primero the Mayo neighborhood.

\section{THE CONCEPT OF HABITABILITY}

The concept of habitability is usually understood as an environment's potential to support life of any kind. The concept of habitability is a sustainability factor in the human environment and in the relationship between the social dimension and environmental dimension (Brundtland, 1987, p. 37). In brief, economic, environmental and social dimensions must be considered together to fully assess sustainability (Sikdar, 2003). For example, the new Construction Code of Bogotá (Secretaría-de-Planeación-Distrital, 2015) gave different solutions to the quality of habitability in the city. One of these recommendations was to update the building laws of the city. 
As a result, the Mayor of Bogotá has integrated the topic of habitability as a sustainability factor into the city's policies. Unfortunately, the user's spatial adaptation needs were not included in the laws. More than ever, flexibility is a necessary condition to understand the concept of habitability, since the construction of new buildings can only be successfully achieved through change and transformation. It is essential to include this variable in the sustainable design process. Thus, the identification of flexibility and social patterns is fundamental in achieving the above.

\subsection{FLEXIBILITY}

Flexibility is a variable of the regulation of the human environment, because it is the factor which makes change possible. As well as being a necessity, flexibility prevents the collapse of an environment. Five factors were identified: identity, appropriation, necessity, increases in the number of residents and renovation (Cubillos González, 2006, p. 132). For example, the production of buildings in Bogotá does not adequately satisfy the needs of its users. This problem is more visible with residential buildings. These types of buildings present spatial problems, as they are not able to adequately provide the adaptations sought by their users.

These transformations occur because the users seek flexibility. The current response by the constructors is to mass produce housing units which do not take this necessity into account. To understand buildings as a process implies seeing them as part of a concept of habitability and flexibility. To summarize, the habitability factor is a design problem as much as it is a sustainable design problem (Mahdavi, 1998, p. 26). To sum up, if flexibility is a necessary condition for building design in Bogotá, then flexibility must be assessed in the habitability of buildings.

\subsection{SOCIAL PATTERNS}

In our environment, social patterns are evidence of people's ability to adapt to different contexts. People interact with their surroundings, recognizing those types of buildings which respond to their own process of adaptation. Therefore flexibility and social patterns are identified as inter-related elements in recognizing the need for building flexibility (Cubillos González, 2010, p. 132).

The consequence of this is a characterized process which has levels of choices with different possible outcomes. To illustrate this, a certain decision making process is required when arranging different objects in positions according to the desired environment. That is to say, this equates to a hierarchy of control consisting of patterns, and all of these elements constitute a biological analogy. It can be called patterns of control (Cubillos González, 2010, p. 128). In summary, social pattern recognition is a tool used to identify habitability variables. The social patterns allow for the evaluation of the social impact of buildings.

\section{MODEL OF HABITABILITY}

There are two elements that structure the habitability model these are the quality of buildings and the quality of life. Now it will go to explain both concepts.

\subsection{QUALITY OF BUILDINGS}

Today, it is common for buildings to be inadequately designed, causing Sick Building Syndrome (SBS) for the users. This syndrome is a result of poor material selection and low controls of water and air contamination (Kannamma \& Meenatchi, 2014). For that reason it is important to study the concept of habitability, because this concept is an important variable in the design process. Also, the habitability factor identifies other variables, for example, physical 
variables such as comfort, health, satisfaction, etc. All these variables are directly related to the design process. The quality of the built environment has significant implications for people's health (Mahdavi, 1998, p. 23).

The main function of architecture is supplying adequate spatial conditions (Calsa-Tres, Arcas-Abella, Cuchi, \& Altés-Arlandis, 2009, p. 411). Therefore, the quality of buildings is an important element in the evaluation of habitability. The Indicators of Materials are used to analyse the Life Cycle. With these data, buildings have Material elements to respond to the environment. Technology Analysis is used to design responses to extreme changes in the environment, and to better integrate control systems to prevent failures that result in disruptions to environmental behaviour.

\subsection{QUALITY OF LIFE}

Quality of life is social organization comprised of most of the individuals that form it, in a continuous process based on the ability to obtain resources from the environment (Calsa-Tres, et al., 2009, p. 410). For that reason, it is important to study the concept of quality of life, because this concept is a variable in the design process.

This means that the habitability factor has the skill to resist changes without significantly affecting the environment or the buildings' structure. Therefore, a study of the habitability of buildings is necessary because the construction industry in Bogotá needs to design tools to create strategies that lead to the production of buildings and a city which is sustainable. This would improve the quality of life for users.

Figure 1 shows the model of the habitability factor in buildings. This graphic consists of the four main variables. These are the independent variables: building quality, flexibility, quality of life and social patterns. Then there are six dependent variables: technology, environment, materials, efficient resources consumption, lower energy consumption and health. Also, the intersection of these elements permits the quantification of the degree of a building occupancy. This quantification could allow the possibility of identifying the Habitability degree of a building.

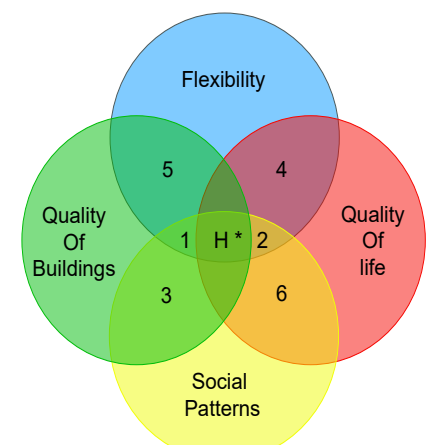

1. High standards for technology / 2. Environment / 3. Lower energy consumption / 4. Efficien resources consumption / 5 . Materials / 6 . Health

${ }^{*} \mathrm{H}=$ Habitability

Fig. 1. Model of Habitability factor 


\section{METHODOLOGY}

The proposed methodology focused its analysis on the relationships between and characteristics of the stated independent variables: quality of buildings, quality of life, flexibility and social patterns. Then, it proceeded to develop a theoretical model detailing the habitability factor analysis in order to assess sustainability in an urban habitat. To identify the relationships between and characteristics of the selected variables, one technique was applied, factor analysis. Factor analysis identified the interrelationship of four independent variables through the construction of a two level matrix. The matrix makes it possible to determine the relationship and the effect of flexibility and social patterns on quality of life and buildings.

The building/construction of the habitability facto is related to the form and use of the space of an urban habitat. The components selected to characterize habitability were: quality of buildings, quality of life, flexibility and social patterns. The first step is to identify the degree of adaptation of a space and the second to identify the type of behavior/activities an inhabitant intends to carry out in a space. Therefore, these four characteristics refer to the physical properties of the space of a habitat.

For this investigation, the habitability variable was determined as the unit of analysis. This selection was made in order to verify if the variable of habitability could be an analysis factor in buildings and habitat. Furthermore, it was found that the concept of habitability is generally discussed in urban and architectural terms, however the mechanisms used to measure the habitability of an urban habitat are unclear. Therefore, it became necessary to define the study variables to eight experimental units and to determine a further future study on the subject.

Consequently, an analysis of habitability factor in habitat and how this influences its response to climate change and sustainability was required. Thus using the analysis matrix eight experimental units were established (Table 1). The results were as follows:

1) Habitability is equivalent to the technology applied to buildings, together with the type of materials used to build them $=($ Technology $\times$ Material $), H=(A 1 B 1) .2)$ Habitability is equivalent to the building technology, together with the efficient resources consumption that the building needs in its life cycle. Habitability $=($ Technology $\times$ Efficient resources consumption), $\mathrm{H}=(\mathrm{A} 1 \mathrm{~B} 2)$. 3) Habitability is equivalent to the Building Technology together with the potential to implement a lower energy consumption strategy. Habitability $=($ Technology $\times$ Lower energy consumption), $\mathrm{H}=(\mathrm{A} 1 \mathrm{C} 1) .4)$ Habitability is equivalent to the Building technology that you can apply in the habitat together with the Healthy environment that can be generated over time. $\mathrm{H}=($ Technology $\times$ Health $) . \mathrm{H}=(\mathrm{A} 2 \mathrm{C} 2)$.

5) Habitability is equivalent to Environment by building materials that make up said urban habitat $=($ Environment $\times$ Material $), R=(A 2 \mathrm{~B} 1) .6)$ Habitability is equivalent to the environment comfort of a habitat by the resources consumption of the same habitat. Habitability $=$ (Environment $\times$ Efficient resources consumption), $\mathrm{R}=(\mathrm{A} 2 \mathrm{~B} 2) .7)$ Habitability is equivalent to the quality of habitat by the potential energy consumption of the said habitat. Habitability $=($ Environment $\times$ Lower energy consumption $), \mathrm{R}=(\mathrm{A} 2 \mathrm{C} 1) .8)$ Habitability is equivalent to the life quality of a habitat by the healthy spaces that can be generated over time. Habitability $=($ Environment $\times$ Health $) . \mathrm{R}=(\mathrm{A} 2 \mathrm{C} 2)$.

In addition, the difference in the average habitability factor for the components Quality of Building (A1) and Quality of life (A2) at the levels of Fexibility (B) and Social Paterns (C) was estimated. Simple effect was observed that s equivalent to (A1 B1) - (A2 B2) - (C1 C2). The main effects of the habitability factor for this model were the difference between the total average for the Quality of Building component and the total average for the Quality of life component, that is, (A1) - (A2). Finally, the secondary effects or the interaction of the Habitability factor estimated by the difference of the experimental units: [(A2 C2) - (A2 C1) - (A2 $\mathrm{B} 2)-(\mathrm{A} 2 \mathrm{~B} 1)]-[(\mathrm{A} 1 \mathrm{C} 2)-(\mathrm{A} 1 \mathrm{C} 1)-(\mathrm{A} 1 \mathrm{~B} 2)-(\mathrm{A} 1 \mathrm{~B} 1)]$. 
Habitability

\begin{tabular}{cccccc}
\hline & & Flexibility & (Factor 3) & Social patterns & (Factorn 4) \\
\hline \multirow{2}{*}{$\begin{array}{c}\text { Quality of Building } \\
\text { (Factor 1) }\end{array}$} & ITEM & Material B1 & $\begin{array}{c}\text { Efficient resources } \\
\text { consumption B2 }\end{array}$ & $\begin{array}{c}\text { Lower energy } \\
\text { consumption C1 }\end{array}$ & Health C2 \\
\cline { 2 - 6 } & \multirow{2}{*}{ Technology A1 } & $\begin{array}{c}\text { Habitability } \\
\text { (A1, B1) }\end{array}$ & $\begin{array}{c}\text { Habitability } \\
\text { (A1, B2) }\end{array}$ & $\begin{array}{c}\text { Habitability } \\
\text { (A1, C1) }\end{array}$ & $\begin{array}{c}\text { Habitability } \\
\text { (A1, C2) }\end{array}$ \\
\hline $\begin{array}{c}\text { Quality of life } \\
\text { (Factor 2) }\end{array}$ & \multirow{2}{*}{ Environment A2 } & $\begin{array}{c}\text { Habitability } \\
\text { (A2, B1) }\end{array}$ & Habitability & Habitability & Habitability \\
& & & & (A2, B2) C1) & (A2, C2) \\
\hline
\end{tabular}

Tab. 1. factorial design of study

To test the Habitability concept it was necessary to carry out fieldwork and implement a pilot. The design experiment consisted in selecting a small urban area that could be observed in its totality and where it is possible to apply all the variables of the study at the same time. For this reason the Primero de Mayo was chosen. This neighbourhood is an important urban habitat in the city and it is located in the fourth district of Bogotá. It is composed of 11 blocks.

The city hall has classified the neighbourhood as a cultural patrimony of the city. This habitat has some urban values that represent an important urban planning example in Bogota. However, currently the neighbourhood suffers a series of user adaptations that compromise its sustainability. The fieldwork consisted in observing the variables of the Habitability model in the neighbourhood. To test the habitability concept it was necessary to design two datasheets to evaluate the variables.

The first datasheet evaluated the Technology variables: Material, Efficient resources consumption, Lower energy consumption and Health. The second datasheet evaluated the environment using the same four variables used in the previous datasheet. Then, a stochastic simulation model was designed. The information of field work was simulated, to do this, the same parameter and fieldwork variables were used. To make the simulation it was necessary to organize three groups of data. Two groups are experimental and the last one was classified as a control Group. 


\section{RESULTS AND DESIGN POTENTIAL}

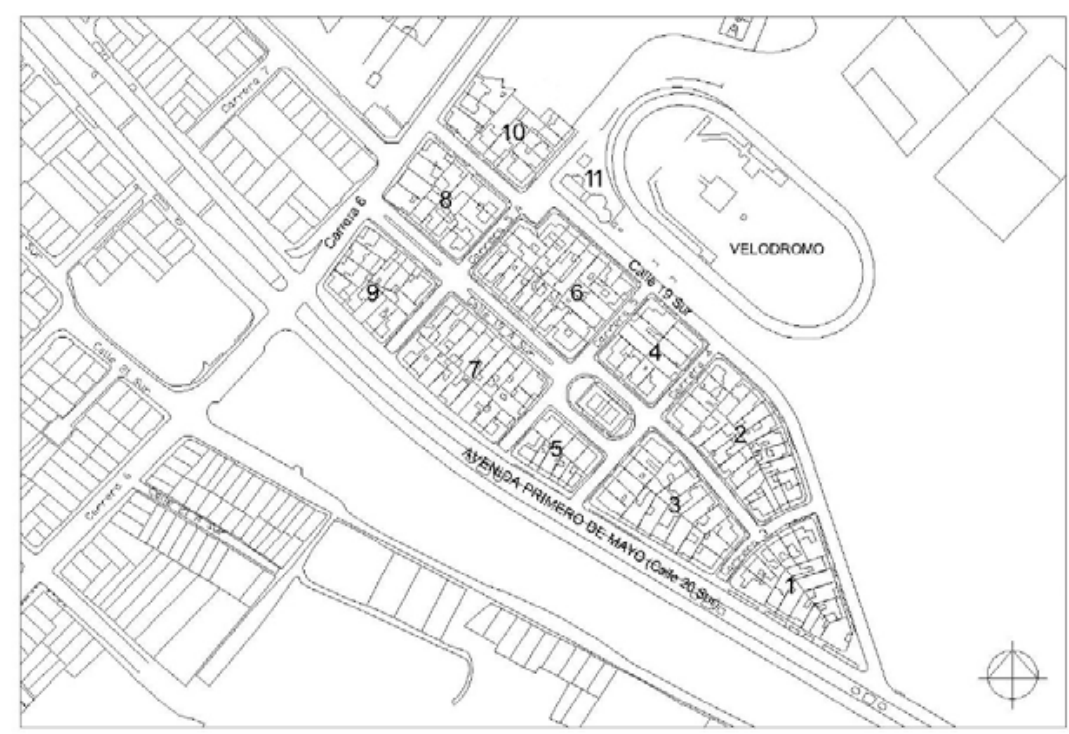

Fig. 2. Primero de Mayo neighborhood

11 blocks were studied in the field work (See Ilustration 1.). The study identified that material is a mediator between indoor conditions and outdoor conditions of buildings, because materials regulated the outdoor conditions to give good habitability to human beings in a building. In the Primero de Mayo neighbourhood, materials do not have a good life cycle. People made a lot of changes to the buildings and mixed different materials without considering the life cycle process. It made the adaptations process unsustainable over time. The City hall regulated the neighbourhood as a cultural patrimony, but that kind of law did not stop the user adaptations of the neighbourhood and the buildings. It is observed that the climate conditions affect the buildings and cause some humidity problems.

This problem was noted in $75 \%$ of buildings. It is most common in the main streets like Avenida Primero de Mayo and Carrera 6a. Also, it was observed that in these main streets the use of buildings was transformed from housing to commercial uses. In the neighbourhood the adaptation process take place over a longer period, but this process is changing the traditional landscape. The datasheet shows that there is not a relationship between all variables of the habitability model. For example, the technology variable is very far from environment variable. That explained the observations in the field work. The material mixes some other problems such as respiratory diseases. This study was not an in depth study of health, therefore it is important to develop a medical study about that topic.

In conclusion, the study shows that currently the habitability factor in the neighbourhood is inefficient, and it is possible that the sustainability of the neighbourhood would be in danger soon. It is important to implement a series of strategies to give a better point of view to design sustainable strategies; a simulation model was created to test the habitability factor for future use in the neighbourhood.

Then, an experiment was performed using MS Excel. First, the calculations were carried out by entering random numbers into an array of different proposed variables. The model was measured by 30 simulations divided in three groups. To give a better objective viewpoint, the groups were divided into two parts. The first was the control group (Group 1) and the others 
were the experimental groups (Group 2 and 3). Then the overall effect, the single effects, the main effect and the effect of interaction between variables were calculated. It important to mention that the simulation was a sthocastic process, meaning that the variables were studied from the present day in order to preview future scenarios.

It was observed that, with regards to the overall effects of the interrelationship between the study variables, each affected the urban habitat in a similar manner. For example, the main impact without any sustainable strategy is $7.5 \%$ on base information field work. The control group shows the impact is $6.5 \%$ if sustainable strategies were implemented. The experimental groups shows that if you combine two of three variables at the same time the environmental impact is from $1.30 \%$ to $1.25 \%$. This demonstrated the important impact of sustainable strategies (see chart 1). However, these kinds of actions would have secondary effects that in the case of Primero de Mayo and group 1 are from $4.0 \%$ to $6.4 \%$. On the other hand, groups two and three show from $2.7 \%$ to $1.64 \%$ of enviroment and technology impact. In all these cases these percentages are negative (See chart 2.).

One can see that the main effect is reflected in the behaviour of the Technology and enviroment variables, with respect to the Habitability factor. The results of the model show that a high environmental impact on an urban environment affects the habitability conditions. The model shows that a high environmental impact affects the flexibility. That is, the Habitability of an urban habitat depends on the culmination of several actions that together respond to the affected system. Finally, the model shows that the variables of energy efficiency versus the material element of habitability affect the buildings and this in turn affects the flexibility variables of an urban habitat. This means that there will be a greater need for Habitability, since the urban habitat may not have the capacity to respond to user's changes (See chart 3 ).

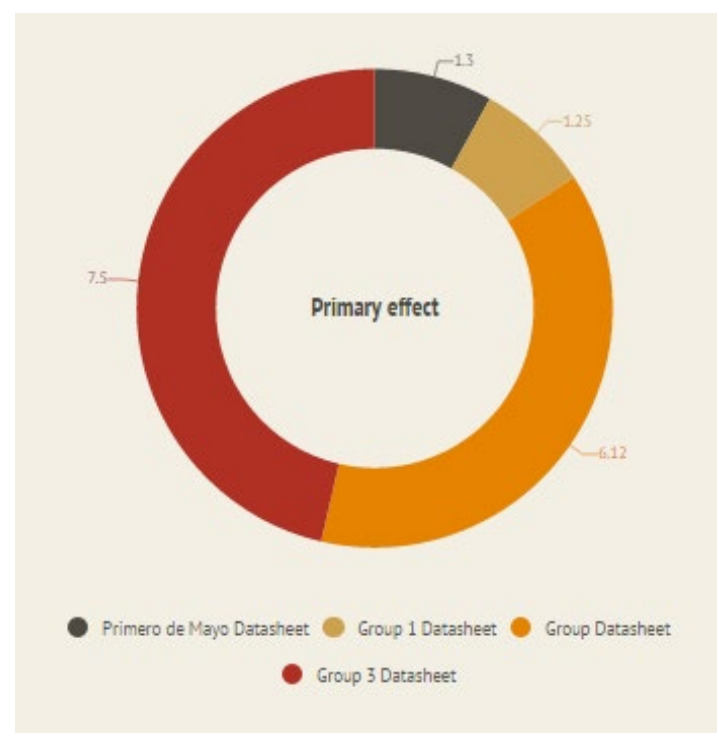

Chart 1. Primary effects results 


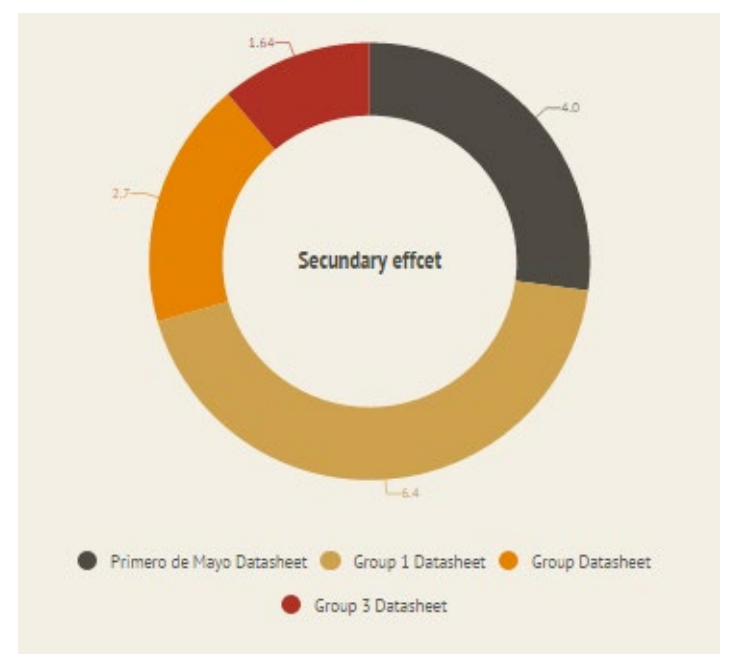

Chart 2. Secondary effects results.

\section{Relationships}

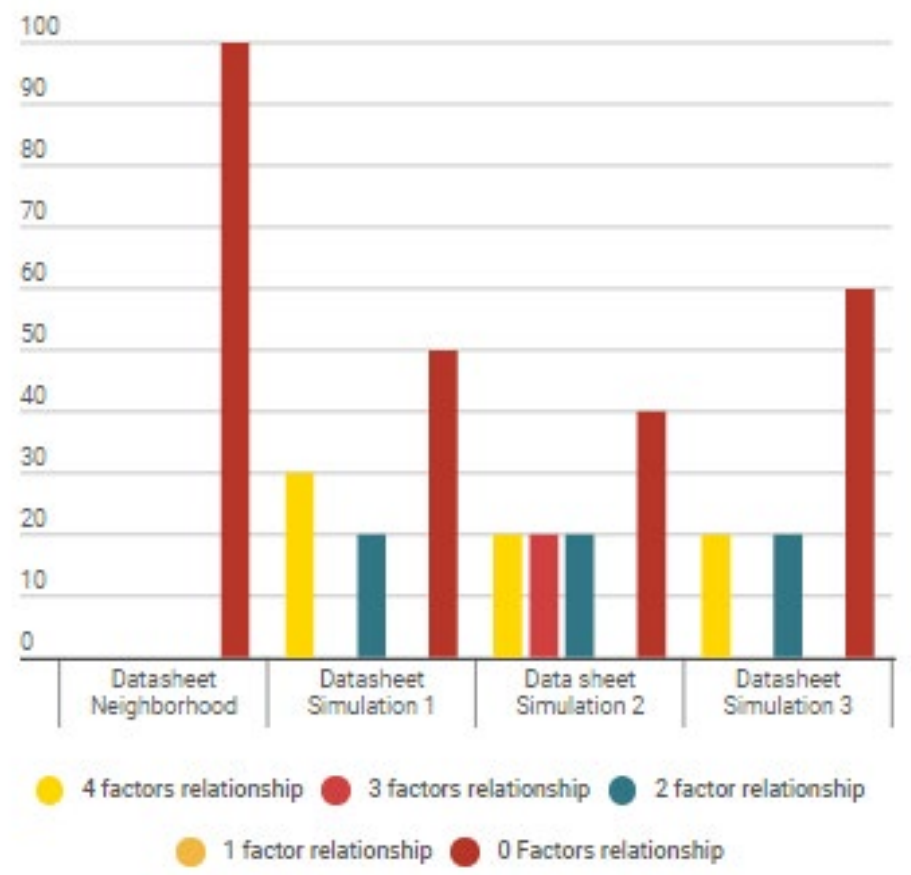

Chart 3. Result of relationships factors 


\section{CONCLUSION}

This study identifies the importance of satisfying the need for Habitability today in Bogotá, and consequently, the results propose to implement a model that can respond to such a need, and to implement and optimise the sustainability of an urban habitat. The model determined the behaviour of the different variables involved and in turn the flexibility that an urban habitat has to have in order to implement optimum conditions of Habitability. Therefore, Habitability occurs when different components of the habitat adapt to reduce their impacts and continue to operate optimally without major losses.

This research study left open the concept of habitability as an endpoint of sustainable buildings. It also identified the role of habitability in the process of building design and targeted different user needs regarding sustainability. The study opens the possibility for buildings to be oriented around strategies and responds to different agents which affect the habitability of buildings. Furthermore, the model proposes an opportunity to develop new sutainable design tools. Finally, the different users' needs from a building were identified through modeling and simulation variables.

\section{ACKNOWLEDGMENTS}

Special Thanks to Vicky Cox who made the edited this article.

\section{REFERENCES}

Arévalo, D. (2014). Implementación del sistema de certificación LEED en Colombia (pp. 17-17). Bogotá.

Brundtland, G. H. (1987). Our common future. General Assembly (pp. 400). New York: United Nations.

Calsa-Tres, M., Arcas-Abella, J., Cuchi, A., \& Altés-Arlandis, A. (2009). HABITABILITY, THE SCALE OF SUSTANINABILITY. DIVA, 409-414.

Cubillos González, R. A. (2006). Vivienda social y flexibilidad en Bogotá. Bitacora Urbano Territorial, 10(1), 124-135.

Cubillos González, R. A. (2010). Sistema de gestión de información de proyectos de vivienda social (SGIPVIS). Revista de Arquitectura, 12, 90-101.

Edwards, B. (2005). Rough guide to sustainability. London: RIBA Enterprises Ltd.

Escallón-Gartner, C., \& Villate-Matiz, C. (2013). Código de construcción para Bogotá: evaluación y propuesta de actualización en el marco de la sostenibilidad. Cuadernos de Vivienda y Urbanismo, 6(12), 248-259.

Kannamma, D., \& Meenatchi, S. (2014). Design Best Practice Methods To Minimize the Impact of Building Materials on Urban Microclimate.

Mahdavi, a. (1998). Steps to a general theory of habitability. Human Ecology Review, 5(1), 23-30.

Ozuna, A., \& Rivera, J. (2012). Sustainable Construction in Colombia: Main Actors and Implementation. IRBNet, 1-11.

Secretaría-de-Planeación-Distrital. (2015). DOCUMENTO EJECUTIVO POLÍTICA PÚBLICA DE ECOURBANISMO Y CONSTRUCCIÓN SOSTENIBLE DE BOGOTÁ. Bogotá: Alcaldía Mayor de Bogotá.

Sikdar, S. K. (2003). Sustainable development and sustainability metrics. AIChE Journal, 49(8), 1928-1932. doi: 10.1002/aic.690490802. 